Short Communication

\title{
AN AWARENESS PROGRAM ON PREVENTION OF VAGINAL CANDIDIASIS AM ONG PREGNANT WOMEN
}

\author{
Pratibha Kamath ${ }^{1}$, Maria Pais ${ }^{2}$, Malathi G. Nayak ${ }^{3} \&$ Clara Pramila D'souza ${ }^{4}$ \\ ${ }^{1,2,3 .}$ Assistant Professors, M anipal College of Nursing, Manipal, Manipal University, ${ }^{4}$ Assistant Lecturer, \\ Manipal School of Nursing, Manipal - 576 104, Karnataka, India. \\ Correspondence : \\ Malathi G. Nayak \\ Assistant Professor- Senior Scale, Community Health Nursing Department \\ Manipal College of Nursing, Manipal University, Manipal - 576 104, Karnataka, India. \\ Mobile : +919449586431 E-mail : malathinayak@yahoo.co.in
}

\begin{abstract}
:
Introduction: Vaginal candidiasis common problem among pregnant women. According to Jumbo G.T.A et al., during pregnancy women who did not know Candidiasis as a disease were $94.1 \%$ and $83.6 \%$ of the respondents felt there was no compelling need for treatment while $86.3 \%$ did not consider the disease of any seriousclinical significance ${ }^{1}$.

Objective : This study was conducted to find the effectiveness of an awareness programme on prevention of vaginal candidiasis among pregnant women in selected seven Rural M aternity Child Welfare centres (RM CW's) of Udupi district.

Materials and M ethod : Evaluative survey approach was used to find the effectiveness of awareness program. The sampling technique used was non probability convenient sampling. Total of 142 pregnant women those who visited antenatal clinics of RM CW's were selected. One group pre-test - post-test design was used to assess the knowledge by administering a structured knowledge questionnaire, followed by awareness program. On seventh day post-test was conducted using same questionnaire to evaluate the knowledge of the subject.

Result: M ajority of the pregnant women (89.2\%) had poor knowledge in pre-test whereas $95.8 \%$ of them acquired a good know ledge in post-test.

Conclusion: Health professionals caring for pregnant women should find out about symptoms of vaginal candidiasis and they can give them knowledge and make aware, which may help them in improving their health by adopting preventive measures and help them to avoid the complications.
\end{abstract}

Key words: vaginal candidiasis, knowledge, pregnant women, awareness program

\section{Introduction:}

Among all motivations of women motherhood is the most universal and the strongest. M otherhood is a beautiful and joyous experience to a woman. The feeling of a life growing inside makes her ecstatic. The health of the mother during pregnancy is important to give birth to a healthy baby. Reproductive tract infections are common during pregnancy and vaginal Access this article online Quick Response Code

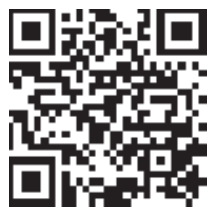
candidiasis (moniliasis or thrush) is a most common and frequently distressing infection for many pregnant women.

Wilkinson described vaginal Candidiasis for the first time in 1849. Vaginal candidiasis is a fungal or yeast infection of the vulva and/or vagina. Candida albicansis the predominant species causing $70-90 \%$ of cases. Most women experience a vaginal candida infection at some point in their lifetimes (Edwards 2004) and 40-45\% will have two or more episodes; about 75\% (M itchell H 2004) of cases occur during the reproductive years. Recurrent vulvo-vaginal candidiasis (RVVC), also known as chronic recurrent thrush, is a largely unrecognized but highly debilitating condition, which affects an estimated 3-6\% of women worldwide. In the United States, candida is the second most common cause of vaginal infections. ${ }^{2}$

Parveen $\mathrm{N}$ et al., conducted a descriptive cross-sectional study among 110 pregnant women in Isra University, Hyderabad in 2008, to identify the frequency of vaginal 
candidiasis in pregnant women attending routine antenatal clinic. Vulva and vagina were inspected for signs of inflammation and discharge with sterile speculum and vaginal specimens were collected with sterile cotton tipped swabs. Swabs were subjected to Gram staining and examined microscopically for the diagnosis of candidiasis. Result revealed that frequency of vaginal candidiasis during pregnancy was found to be $38 \%$, in which $27 \%$ were symptomatic and $11 \%$ were asymptomatic group, increased ratio of infection was observed in multigravida and diabetic women. ${ }^{3}$

Women are unlikely to seek advice because there is a tendency to view "white discharge" as normal and also because the condition is associated with shame and guilt. Usually women complain of vaginal discharge when they think it is unusual for them or if it causes itching or discomfort. ${ }^{4,5}$

The need for the study arises from the facts gathered from the few research studies focused on this area of health related issues, also the incidents the researcher come across in day to day life. This study has been taken up and supported by above stated studies and the data. It is evident from the above cited studies that, vaginal candidiasis is common during pregnancy and pregnant women are at high risk of developing it. So, the investigator strongly felt the need of conducting a to assess the knowledge of pregnant women regarding vaginal candidiasis and to find the effectiveness of an awareness program on prevention of vaginal candidiasis among the rural pregnant women who are attending the Rural M aternal \& Child Welfare centers of Kasturba Hospital , Manipal. With the help of awareness programme, pregnant women can be given information regarding vaginal candidiasis and need based care can be implemented hence, pregnant women can be motivated to seek timely medical advice for health problems.

\section{Materialsand Method:}

In order to achieve the objective of the study, an evaluative approach was used to find the effectiveness of awareness programme on prevention of vaginal candidiasis. One group pre-test - post-test design was used to assess the knowledge. Data was collected by using non-probability convenient sampling from 147 pregnant women who fulfilled the sampling criteria and from those who were available during the period of data collection. Structured knowledge questionnaire was used to assess the knowledge and a modified Srivastav So cio economic status scale to assess the socio economic background. Descriptive and inferential test was performed by using SPSS version 16.

\section{Results:}

\section{Description of sample characteristics:}

Data shows that most of the pregnant women (52.8\%) belonged to the age group of $26-33$ years. $57 \%$ were in $3^{\text {rd }}$ trimester of pregnancy, $80.3 \%$ of them belonged to Hindu religion. Majority of the pregnant women (83.14\%) belonged to moderate socio economic status. (Table 1 )

\section{Description of sample based on pre-test post-test Knowledge scores}

The structured knowledge questionnaire on prevention of vaginal candidiasis was used to assess the pre-test knowledge of 147 pregnant women and there was a sample mortality of 22 pregnant women during the posttest. So 120 pregnant women's data was only available for further analysis. The maximum score for knowledge questionnaire was 16 and the scores were categorized arbitrarily. Out of 120 pregnant women $89.2 \%$ had poor knowledge in pre-test; where as $95.8 \%$ had good knowledge in post-test on prevention of vaginal candidiasis.

\section{Computation of effectiveness of awareness program in terms of gain in knowledge scores.}

Effectiveness of the awareness program was computed by Paired t test as shown in Table 2. Using paired t test (pre and post) investigator observed that, $t=-23.45, \mathrm{df}=119$ and $p$ value $<0.001$, there was significant difference between pre-test and post-test mean, $\mathrm{Cl}(-5.66-4.78)$.

\section{Association between pre-test knowledge scores with selected variables}


The significance of association was computed using Chisquare. Data show that there is no significant association between pre-test knowledge score and selected demographic variables. Thus it can be inferred that risk status of vaginal candidiasis is independent of selected demographic variables. (Table 3)

Table 1: Frequency and percentage of sample characteristics.

\begin{tabular}{lcc} 
& & $\mathrm{n}=142$ \\
\hline Sample Characteristics & $\mathbf{f}$ & $\%$ \\
\hline Age in years & 56 & 39.4 \\
$18-25$ & 75 & 52.8 \\
$26-33$ & 11 & 7.7 \\
$34-40$ & & \\
Trimester of pregnancy & 15 & 10.6 \\
$1^{\text {st }}$ & 46 & 32.4 \\
$2^{\text {nd }}$ & 81 & 57 \\
$3^{\text {rd }}$ & & \\
Religion & 114 & 80.3 \\
Hindu & 0 & 0 \\
Christian & 28 & 19.7 \\
M uslim & & \\
Health information source & 11 & 7.7 \\
News paper & 05 & 3.5 \\
Magazines & 41 & 28.9 \\
Television & 10 & 7.0 \\
Radio & 48 & 33.8 \\
Health Personnel & 19 & 13.14 \\
Family members & 03 & 2.1 \\
Friends & 05 & 3.5 \\
Neighbors & & \\
Socio Economic Status & 10 & 7.0 \\
Low & 118 & 83.14 \\
M oderate & 14 & 9.9 \\
High & & \\
\hline & & \\
\hline & &
\end{tabular}

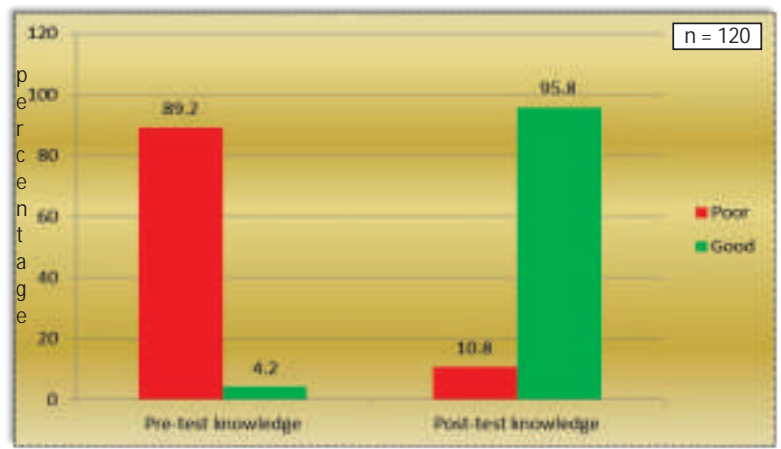

Fig 1: Frequency and percentage distribution of pre-test and posttest knowledge scores on prevention of vaginal candidiasis.
Table 2: M ean and Standard Deviation value of pre-test and posttest of knowledge scores of the pregnant women on prevention of vaginal candidiasis.

$n=120$

\begin{tabular}{|l|c|c|}
\hline Knowledge & Mean & SD \\
\hline Pre-test & 5.74 & 2.25 \\
\hline Post-test & 10.97 & 1.77 \\
\hline
\end{tabular}

Table 3: Chi-square value showing the association between pretest knowledge score and selected variables $\quad n=120$

\begin{tabular}{|c|c|c|c|c|c|}
\hline \multirow[t]{2}{*}{ Variables } & \multicolumn{2}{|c|}{ Knowledge } & \multirow[t]{2}{*}{$\chi^{2}$} & \multirow[t]{2}{*}{ Df } & \multirow[t]{2}{*}{ P value } \\
\hline & Poor & Good & & & \\
\hline Age in years & & & 1.219 & 2 & 0.355 \\
\hline $18-25$ & 44 & 05 & & & \\
\hline $26-33$ & 55 & 08 & & & \\
\hline $34-40$ & 08 & 0 & & & \\
\hline \multicolumn{6}{|c|}{ Trimester of pregnancy } \\
\hline $1^{\text {st }}$ & 10 & 1 & 2.046 & 2 & 0.345 \\
\hline $2^{\text {nd }}$ & 29 & 6 & & & \\
\hline $3^{\text {rd }}$ & 68 & 6 & & & \\
\hline \multicolumn{6}{|l|}{ Religion } \\
\hline Hindu & 86 & 10 & .086 & 1 & 0.722 \\
\hline Muslim & 21 & 03 & & & \\
\hline \multicolumn{6}{|l|}{ SESS } \\
\hline Low & 7 & 01 & 0.026 & 2 & 1 \\
\hline Moderate & 92 & 11 & & & \\
\hline High & 08 & 01 & & & \\
\hline
\end{tabular}

\section{Discussion :}

The pre-test data showed $89.2 \%$ of the pregnant women had poor knowledge, where as $95.8 \%$ had good knowledge in post-test. The following study finding supported this study finding.

Thankamma M.S. conducted a study in Udupi district, the result revealed that, in experimental group 22(73.33\%) scored good in pre-test, whereas in control group 13(43.33\%) participants scored good score in pre-test. But in the post test experimental group exhibited 100\% knowledge, whereas control group exhibited only $90 \%$ knowledge. $^{6}$

The findings of the present study indicated that, mean percentage of post-test knowledge score (10.97) was higher than that of pre-test mean percentage score (5.74). There was significant difference between the mean pretest and post-test knowledge scores of the samples ( $t=$ 23.45 and $p=\varangle 0.001$ )

The above finding from the present study is supported by 
the study which is conducted by the Oesman $\mathrm{MH}$ et al., in Italy, the findings of the study revealed that there was a significant gain in knowledge for patients who viewed the video tape $(\mathrm{t}=5.43, \mathrm{df}=213, \mathrm{p} \varangle 0.05$ ) and they were more satisfied with their education compared with the control group $(t=4.75, d f=213, p<0.001)^{7}{ }^{7}$

Chi-square was computed between pre-test knowledge scores and selected demographic variables showed that

\section{References :}

1. Jombo, G.T.A., Akpera, M.T., Hemba, S.H., and Eyong, K.A. Symptomatic vulvi vaginal

2. Available from: http://overcoming candida.com/vaginal_ candidiasis.htm

3. Parveen N, M unir AA, Din I, M ajeed R: Frequency of vaginal candidiasis in pregnant women attending routine antenatal clinic.j Coll Physicians Surg Pak.2008 M ar;18(3). Available from:

4. Dixon-Muller R. Gender Inequalities and Reproductive Health:Changing priorities in an Era of social Transformation and Globalization. International union for the Scientific study of population. European Journal of Scientific Research.2008;2:(7). Available from.

5. Sharma M, Sethi S, Gopalan S, Gulat K, Lyall S. Seroprevalence of reproductive tract infections in women in northern India relatively low prevalence area. NIHFW Newsletter. 2004:6(3). Available from http://www.nmji.in/archives/Volume_17-

6. Thankamma MS. A randomized contrölled trial of videoteaching over lecture cum demonstration in improving knowledge and skill of nursing students on antenatal examination in selected college of nursing in udupi district. 2008 August.

7. Oesman MH, Webb SA and Share JA. Outcome of videotape instructions in clinic waiting area. Orthopedic nursing. 2003;12(6):102-105

8. Malathi k. Effectiveness of Planned Teaching Regarding M anagement of BPH on BPH patients. The Nursing J ournal of India.2009; (9) there was no significant association between pre-test knowledge scores and selected demographic variables. The present study supported by the study conducted by Malathi K. a study on Effectiveness of Planned Teaching Regarding Management of BPH on BPH patients, result revealed that there was no significant association between the pre-test levels of knowledge with selected variables. ${ }^{8}$ 